\title{
Particles on the Move: Intracellular Trafficking and Asymmetric Mitotic Partitioning of Nanoporous Polymer Particles
}

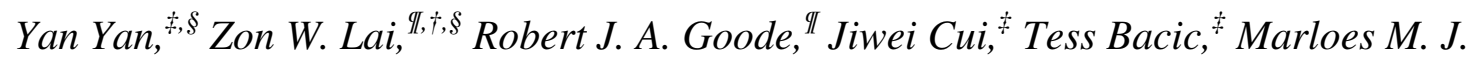

Kamphuis, ${ }^{\ddagger}$ Edouard C. Nice, ${ }^{\mathscr{I}, *}$ and Frank Caruso ${ }^{\ddagger} *$

${ }^{\ddagger}$ Department of Chemical and Biomolecular Engineering, The University of Melbourne,

Parkville, Victoria 3010, Australia, "Department of Biochemistry and Molecular Biology,

Monash University, Victoria 3800, Australia, and ${ }^{\dagger}$ Institute for Molecular Medicine and Cell

Research, University of Freiburg, Freiburg 79104, Germany

AUTHOR EMAIL ADDRESS: fcaruso@unimelb.edu.au, ed.nice@monash.edu,

${ }^{\S}$ These authors contributed equally. 


\begin{abstract}
Nanoporous polymer particles (NPPs) prepared by mesoporous silica templating show promise as a new class of versatile drug/gene delivery vehicles owning to their high payload capacity, functionality, and responsiveness. Understanding the cellular dynamics of such particles, including uptake, intracellular trafficking and distribution, is an important requirement for their development as therapeutic carriers. Herein, we examine the spatiotemporal map of the cellular processing of submicron-sized disulfide-bonded poly(methacrylic acid) (PMA $\mathrm{PHH}_{\mathrm{SH}}$ NPP in HeLa cells using both flow cytometry and fluorescence microscopy. The data show that the PMA NPPs are transported from the early endosomes to the lysosomes within a few minutes. Upon cell division, the lysosome-enclosed PMA $\mathrm{SH}_{\mathrm{SH}}$ NPs are distributed asymmetrically between two daughter cells. Statistical analysis of cells during cytokinesis suggests that partitioning of particles is biased with an average segregation deviation of $60 \%$. Further, two-dimensional difference gel electrophoresis (2D-DIGE) analysis reveals that 127 out of 3059 identified spots are differentially regulated upon exposure to the PMA $\mathrm{SH}_{\mathrm{SH}}$ NPP. Pathway analysis of the proteomics data suggests that ubiquitylation, a reversible modification of cellular proteins with ubiquitin, plays a central role in overall cellular responses to the particles. These results provide important insights into the cellular dynamics and heterogeneity of NPPs, as well as the mechanisms that regulate the motility of these particles within cells, all which have important implications for drug susceptibility characteristics in cancer cells using particle-based carriers.
\end{abstract}

KEYWORDS: mesoporous silica particles, mitotic partitioning, asymmetric division, intracellular fate, proteomics, ubiquitylation 
In recent years there has been growing interest in investigating and understanding cellular interactions of nanoengineered particles, as their cellular dynamics can inform key aspects for ensuring safe and effective therapeutic delivery using particle carriers. Previous studies have shown that endocytosis provides a major route for cellular entry, and that the lysosomal compartment is the predominant intracellular destination for different types of particles. ${ }^{1,2}$ While current work is heavily focused on mapping endocytic pathways involved in particle internalization, ${ }^{3}$ the cellular processing beyond lysosomal accumulation of incoming particles is generally poorly understood.

Traditionally, endocytosis has been regarded simply as a process for ingesting external molecules prior to digesting them, or recycling them back to the cell surface. ${ }^{4}$ More recently, it has become clear that the endocytic systems are intimately connected with other seemingly disparate cell functions, such as cell migration, antigen presentation and cell division. ${ }^{5,6}$ For example, asymmetric partitioning of endosomes has been observed at the initial cleavage of both the C. elegans embryo $^{7}$ and mammalian haematopoietic stem cells. ${ }^{8}$ Such asymmetric distribution results in an unequal partitioning of key signaling molecules (i.e., Notch and Delta) between two daughter cells, which may be pivotal in the maintenance of the stem cell niche. The understanding of how internalized particles redistribute when the original cell divides into two daughter cells is particularly important for proliferative cells, such as cancer cells, as cell division would lead to dilution of the intracellular particle concentration (and hence drug payload) during therapy. To date, few studies have reported on the distribution of particles during cell division despite the fact that many different types of nanoengineered particles have been generated. It has been shown that nanodiamonds ${ }^{9}$ and silica microparticles ${ }^{10}$ are equally distributed between two daughter cells, whereas, by contrast, the dilution of quantum dots ${ }^{11,12}$ 
upon cell division leads to asymmetric segregation. The different patterns of mitotic partitioning observed in such studies suggest that internalized particles, which have accumulated in the endocytic systems, may be further regulated during cell division. Investigations on the deterministic and stochastic mechanisms of particle partitioning are likely to shed light on the particle heterogeneity at the cell population level, providing a global landscape of cellular dynamics.

A number of polymer-based particle systems have been developed to facilitate drug solubility and improve drug pharmacokinetics, such as self-assembled polymersomes and micelles. ${ }^{13}$ Alternatively, templated assembly, which is a simple and versatile fabrication process, has emerged as a key approach in the preparation of polymer particles with well-defined and controllable physicochemical properties. This is exemplified by the development of a suite of polymer particles/capsules with controlled size, shape, and surface functionalization through layer-by-layer (LbL) assembly using nonporous particle templates. ${ }^{14,15}$ Templating porous particles, which involves polymers infiltrating the internal pore network, has yielded a new class of replica particles, termed nanoporous polymer particles (NPPs). ${ }^{16,17}$ Such polymer particles exhibit high cargo loading capacity due to their large surface area as a result of the porous templates. Mesoporous silica (MS) particles have been employed in the generation of a range of NPPs with different chemical composition, including polypeptides, synthetic polyelectrolytes, and polysaccharides. ${ }^{16,17}$

Recently, progress has been made in applying NPPs for therapeutic delivery in a number of pathological scenarios. ${ }^{18-20}$ For example, nanoporous poly(L-glutamic acid) particles have been developed to deliver a brain-derived neurotrophic factor (BDNF) in an animal model to rescue neuronal cells that have lost their endogenous neurotrophin supply, ${ }^{18}$ whilst nanoporous poly(L- 
lysine) particles have been used to codeliver a plasmid DNA and a peptide hormone for concurrent stimulation of melanogenesis in mammalian melanocytes. ${ }^{19}$ Recently, we reported a novel drug-loaded particle system which combines drug-polymer conjugates and MS templating. ${ }^{20}$ These particles are prepared by infiltration of drug-conjugated thiolated poly(methacrylic acid) (PMA ${ }_{S H}$ ) into submicron-sized MS particles, followed by subsequent oxidation of the thiol groups in the $\mathrm{PMA}_{\mathrm{SH}}$ to form stable disulfide bonds, and dissolution of the silica templates. The resulting drug-loaded $\mathrm{PMA}_{\mathrm{SH}}$ particles exhibit excellent monodispersity and are cytotoxic to colorectal cancer cells. ${ }^{20}$ Given the simplicity of this approach, PMA SH NPPS $_{\text {N }}$ present an interesting therapeutic delivery particle system for biological applications. However, detailed studies on the cellular interactions of NPPs, and subsequent particle partitioning during cancer cell division, are yet to be performed.

Herein, we examine the cellular interactions, intracellular fate, mitotic partitioning, and cellular responses of $\mathrm{PMA}_{\mathrm{SH}}$ NPPs. Our results show that these particles are effectively internalized by HeLa cells, traffic from early endosomes to lysosomes within a few minutes, and ultimately accumulate in the lysosomal compartments. Using both time-lapse and static fluorescence microscopy, we show that upon cell division, these lysosome-enclosed particles are distributed asymmetrically between two daughter cells. Additionally, proteomics techniques, based on 2D-DIGE and liquid chromatography coupled with tandem mass spectrometry (nano LC-MS/MS), have been used to elucidate potential underlying cellular mechanisms. We have identified 18 proteins that are differentially regulated. Importantly, all of these 18 proteins strongly align with the ubiquitylation network, suggesting a critical role of ubiquitylation in particle trafficking and sorting. Taken together, our data provide novel insights into cellular interactions of $\mathrm{PMA}_{\mathrm{SH}}$ particles with respect to their intracellular trafficking and mitotic 
partitioning, which has implications in particle dynamics at both single cell and cell population levels.

\section{RESULTS AND DISCUSSION}

The PMA ${ }_{S H}$ NPPs used in this study were prepared as described previously, ${ }^{20}$ and were characterized by transmission electron microscopy (TEM), dynamic light scattering (DLS) and microelectrophoresis. These particles are monodisperse with an average diameter of $500 \pm 50 \mathrm{~nm}$ (from TEM and DLS) (Figure $1 \mathrm{a}$ and $\mathrm{b}$ ) and exhibit a zeta(ל)-potential of -38 mV. Subsequently, the particles were labeled with Alexa Fluor 633 (AF633) to allow qualitative and quantitative analyses using fluorescence-based techniques, including flow cytometry, imaging flow cytometry, and deconvolution microscopy. The cellular association of the particles was evaluated at a constant particle concentration $\left(7.5 \times 10^{3}\right.$ particles $\mu \mathrm{L}^{-1}$; particle-to-cell ratio of $\left.100: 1\right)$ as a function of time. It was shown that the percentage of cells associated with the PMA $\mathrm{SH}_{\mathrm{NPP}}$ increased with incubation time and reached a plateau of $\sim 95 \%$ at $16 \mathrm{~h}$ (Figure 1c and d). Based on these cellular association kinetics, cells were incubated with PMA $\mathrm{SH}_{\mathrm{SH}}$ particles for $24 \mathrm{~h}$ for subsequent internalization, intracellular fate, and mitotic partitioning analyses.

To quantitatively analyze the cellular uptake of the PMA $\mathrm{A}_{\mathrm{SH}}$ particles, imaging flow cytometry, which integrates flow cytometry and fluorescence imaging, ${ }^{21}$ was employed. Following treatment with the particles, cells were labeled with Vybrant CFDA SE Cell Tracer to mark the outline of the cells. By using the internalization feature in the IDEAS software, the probability of particle uptake was evaluated as an Internalization Score (IS). Based on the acquired images of the cells and the particles, the location of the particles in relation to the intracellular or extracellular space can be quantitatively analyzed by the IDEAS software. Cells with 
internalized particles give a positive IS. As shown in Figure 2, about $85 \%$ of cells with IS $>0$ showed substantial uptake of the particles, which is consistent with previous reports that submicron-sized PMA $\mathrm{SH}_{\text {capsules are readily internalized by a range of cells. }}{ }^{21,22}$

Next, we sought to acquire detailed information on the intracellular trafficking of the PMA $\mathrm{SH}_{\mathrm{SH}}$ particles. In this study, we examined the subcellular destination of PMA $\mathrm{SH}_{\mathrm{SH}}$ particles using deconvolution microscopy in both static and real time modes. By cotransduction of HeLa cells with CellLight Early Endosomes-GFP and CellLight Lysosomes-RFP, we were able to track the mobility of the internalized PMA $\mathrm{A}_{\mathrm{SH}}$ particles between early endosomes and lysosomes. The live cell imaging showed that single particles were initially associated (vesicle fusion) with early endosomes, which encircled the internalized particles (Figure 3, Frames 1 and 2). In the following $5 \mathrm{~min}$, individual particles gradually disassociated (vesicle fission) from the early endosomes (Figure 3, Frames 3 and 4). Ultimately, the particles increasingly colocalized with lysosomes (Figure 3, Frames 5-12), indicating directed particle trafficking from early endosomes to lysosomes, which is also observed for other nanoparticles. ${ }^{23}$ This rapid trafficking of particles from early endosomes to lysosomes within a few minutes was observed in four independent time-lapse live cell experiments. An additional example where the trafficking between early endosomes to lysosomes was about $7.5 \mathrm{~min}$ is shown in Figure S1. The final intracellular distribution of the particles was further confirmed by immunostaining with the lysosomal

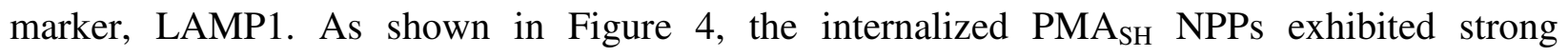
colocalization with lysosomes in the cells that had been incubated with the particles for $24 \mathrm{~h}$. Taken together, our data suggest that following internalization, PMA $\mathrm{AH}_{\mathrm{SP}}$ NPs transiently fuse with early endosomes and ultimately accumulate in the lysosomes as their final intracellular destination after $24 \mathrm{~h}$. 
To examine the impact of the lysosome-trapped particles on mitosis, cell proliferation was evaluated using flow cytometry. Cells were incubated with PMA $\mathrm{SH}_{\mathrm{SH}}$ particles at a particle-to-cell ratio of 100:1 for $24 \mathrm{~h}$, followed by incubation in particle-free complete media for an additional 24 h. Viable cells were counted and compared with untreated cells at each time point. No significant changes in cell proliferation were observed (Figure S2), which is consistent with previous reports that $\mathrm{PMA}_{\mathrm{SH}}$ particles have negligible cytotoxicity. ${ }^{20}$ To understand the particle segregation following cell division at a single-cell resolution, the cell cycle was monitored by time-lapse imaging of cells subsequent to internalization of the PMA $\mathrm{PSH}_{\mathrm{SH}}$ particles. Firstly, cells were transduced with CellLight Tubulin-GFP to labeled microtubules, allowing various phases of the cell cycle to be identified. AF633-PMA $\mathrm{SH}_{\mathrm{SH}}$ particles were introduced into the cells by incubation for $24 \mathrm{~h}$. After removal of excess particles, the cells were imaged for the following 24 $\mathrm{h}$ at $10 \mathrm{~min}$ intervals to monitor the cell cycle. A representative time-lapse series of a single HeLa cell undergoing mitosis is shown in Figure 5. Multiple particles were internalized by the cells and retained in various mitotic phases (prophase, metaphase, anaphase and telophase) without disturbing spindle formation (Figure 5, upper and middle panels). Interestingly, during cytokinesis, the late stage of mitosis when the cytoplasm is divided into two daughter cells, the $\mathrm{PMA}_{\mathrm{SH}}$ particles were asymmetrically segregated between the two cells (Figure 5, lower panels). This asymmetric mitotic partitioning was observed in three independent time-lapse live cell experiments, and an additional example is shown in Figure S3.

To assess the population variation in mitotic partitioning of the particles, we sought to quantitatively evaluate the particle redistribution between the two daughter cells. After exposure to the particles for $24 \mathrm{~h}$, cells were cultured in particle-free growth media for $20 \mathrm{~h}$ to allow them to continue through the cell cycle, as the mean division time for HeLa cells is $20.5 \mathrm{~h} .^{12}$ This 
allows the cell population to progress through the cell cycle in the absence of the particles, which ensures that the particles observed in individual daughter cells were inherited from the parental cells. By immunostaining the microtubules with a mouse anti- $\alpha$-tubulin monoclonal antibody, 152 cells undergoing cytokinesis were identified, and the number of particles in each daughter cell was determined.

In order to quantify the asymmetry, the segregation deviation (\%) was calculated (see Methods for details). The frequency of segregation deviation was plotted (Figure 6). This showed that the segregation deviation peaked at $60 \%$, suggesting dilution of the lysosome-enclosed particles across cell generations is biased. Although the molecular mechanisms of lysosome inheritance are yet to be revealed, studies have suggested that endosomes and lysosomes are partitioned as intact vesicles. ${ }^{24}$ Typically, lysosomes are accumulated in the vicinity of the microtubule organization center during cytokinesis and segregated into daughter cells by coordinated movements in a stochastic fashion. ${ }^{24}$ Although several previous studies have shown that cell division results in a decrease in intracellular concentration of both nanodiamonds and silica microparticles by symmetrical dilution in two daughter cells, ${ }^{9,10}$ by contrast, studies on quantum dots have reported that partitioning during cell division is a random and asymmetric process, resulting in a faster dilution of quantum dots at the cell population level compared to symmetrical segregation. ${ }^{11,12}$ It has been suggested that the mitotic partitioning of internalized particles may be intimately connected to particle-induced cellular stress. ${ }^{12}$ Consequently, asymmetrical division of particles may present a strategy to reduce the risk from an external toxin at the cell population level. ${ }^{12}$

Mass-spectrometry-based proteomics techniques have recently been demonstrated to be powerful tools for investigating cellular mechanisms and analyzing particle-induced cellular 
responses. $^{25}$ To identify differentially expressed proteins in response to PMA $\mathrm{SH}$ NPP exposure for $24 \mathrm{~h}, 2 \mathrm{D}-\mathrm{DIGE}$ and nano LC-MS/MS were employed to compare the overall changes between treated and untreated HeLa cells. Six cell culture replicates of each group were prepared (to allow statistical analysis ${ }^{26}$ ). Half of each set was labeled with Cy3 and the other half with Cy5 DIGE label using a reverse labeling strategy. ${ }^{26}$ Additionally, an internal control was prepared with equal volumes of each extract from both conditions and labeled with $\mathrm{Cy} 2 .^{26}$ Randomly paired samples with opposite labeling and opposing conditions were mixed together with the internal control and separated on pH 3-10 nonlinear $24 \mathrm{~cm}$ IPG strips using cup loading, followed by separation on precast large format $12.5 \%$ gels. Following the 2D separation, gels were scanned on a Typhoon scanner and the images analyzed using the DeCyder software package. Excellent reproducibly was noted between the six replicate gels (Figure S4). DeCyder analysis showed that, of the 3059 spots recognized on the gels, 127 spots were differentially regulated $(n=6, p<0.05$, data not shown). However, the level of change was typically relatively low (less than twofold). This is in agreement with our previous proteomics studies on cellular responses to nanoparticles, indicating that the changes induced were relatively subtle. ${ }^{25}$ Following silver staining, 20 of the 127 differentially regulated spots were deemed suitably abundant for proteomics analysis. A landmark spot (spot 21, S4a) was taken as a reference point. All of these spots yielded interpretable data, and a total of 18 distinct proteins were identified from the major component(s) of each spot with multiple peptides corresponding to each protein identified (Table S1). Several proteins were identified in more than one gel spot, suggesting modifications or different isoforms were detected.

Interestingly, 10 of these proteins (55.5\%) (HNRNPL, EIF4A3, RPLPO, DLD, PKM2, VIM. HSPA8, HSPD1, HNRNPC, ENO1) had been previously identified in a meta-analysis of the 138 
proteins reported in other proteomics-based analyses of cellular responses to nanoparticles on human cells, ${ }^{25}$ confirming that, irrespective of the particle nature, a number of common pathways are regulated following particle uptake by cells.

Notably, 60S acidic ribosomal protein L0 (RPLP0) was identified in two adjacent spots (6 and 7, Figure S4a) of similar molecular weight but with different apparent isoelectric point (pI) values and expression moving in opposite directions, suggesting that either posttranslational modifications or different splicing isoforms were present. Though not definitive, dephosphorylation of RPLP0 following particle exposure is a strong possibility. Additionally, heterogeneous ribonucleoprotein C (HNRNPC) was identified in two spots (18 and 19, Figure S4a) with differing molecular weights. Both of these spots were among the most strongly upregulated in the DIGE analysis, with each displaying a similar increase in expression in particle-treated cells (1.62 and 1.72 fold, respectively). The peptides identified in the two spots clearly differentiated the alternative transcript/protein forms with an additional exon being present in the larger form (Figure S5).

Bioinformatics analysis using Ingenuity Pathway Analysis (IPA) software was performed to interpret the molecular networks and biological functions of the differentially regulated proteins (Figure 7; an enlarged form is provided in Figure S6). Twelve out of 18 of the proteins that we identified were clustered around a network involved in functions of molecular transport and protein trafficking (Figure 7a). While less well populated, 5 out of 18 of the proteins were ascribed a role in molecular transport and RNA trafficking (Figure 7b). Strikingly, the overlay of these two standard networks appeared to feed into the ubiquitylation network (Figure 7c). Traditionally, ubiquitylation has been regarded as a protein degradation mechanism by reversibly modifying proteins with ubiquitin and subsequently directing them to the proteasome. ${ }^{27}$ More 
recently, evidence has demonstrated that ubiquitylation also plays critical roles in nonproteolytic functions, such as endocytosis. ${ }^{28}$ For example, the addition of single ubiquitin moieties to epidermal growth factor receptor (EGFR) cytoplasmic tail induces its internalization and trafficking to lysosomes. ${ }^{29}$ Further, ubiquitylation of cell membrane receptors of several viruses, such as influenza virus ${ }^{30}$ and herpes simplex virus, ${ }^{31}$ is required for virus entry and trafficking. In particular, the balance between ubiquitylation and deubiquitylation has been suggested to govern the efficiency of recycling form endosomes to the plasma membrane versus lysosomal sorting through the multivesicular body pathway. ${ }^{28}$ Taken together, the proteomics data demonstrate that ubiquitylation activities are the major cellular responses to the particles, suggesting the central role of ubiquitylation in regulating the particle uptake and trafficking. Clearly, we are only at the beginning of understanding the ubiquitylation functions in the cell-particle interactions, and more work will be needed to further examine the proteome and identify the cellular proteins that are specifically and reversibly modified in response to the PMA $\mathrm{ASH}_{\mathrm{SP}}$ NP.

\section{CONCLUSIONS}

The present study provides the first investigation of cellular interactions as well as cellular regulatory networks of $\mathrm{PMA}_{\mathrm{SH}}$ NPPs that are being developed for biological applications. The interactions between the PMA $\mathrm{SH}_{\mathrm{SP}}$ NPs and HeLa cells have been qualitatively and quantitatively characterized using various techniques, including fluorescence imaging and proteomics. Our data have shown that the particles rapidly traffic from early endosomes to lysosomes following internalization, which occurs over a few minutes. Using both static and time-lapse imaging modes, this study provides quantitative evidence that the internalized particles are partitioned asymmetrically between two daughter cells upon cell division. The biased segregation of 
particles gives rise to daughter cells that differ in particle dose, providing valuable information on the heterogeneity of particle inheritance. Furthermore, the proteomic analysis has identified a number of differentially expressed proteins upon exposure to the PMA $\mathrm{SH}_{\mathrm{SH}}$ NPs to HeLa cells, and suggests that ubiquitylation is a key signal triggered by the particles. It is also noted that the intracellular mobility of particles is strongly influenced by particles size, shape and surface chemistry, as well as cell physiology. Hence, future studies will be aimed at identify the physicochemical properties of particles that govern cellular processing. ${ }^{32,33}$ Nonetheless, the reported findings shed light on the mechanisms that govern the cellular journey of the particles, from trafficking to inheritance. Understanding the intrinsic regulatory networks of the particles will be key to evaluating their efficacy and safety for their biological applications, and potentially allowing control of particle internalization, trafficking and localization at subcellular levels. 


\section{METHODS}

Materials: Poly(methacrylic acid, sodium salt) (PMA, $\mathrm{M}_{\mathrm{w}} 15 \mathrm{kDa}$ ) was purchased from Polysciences (USA). $N$-chloro-p-toluenesulfonamide sodium salt (chloramine T), hydrofluoric acid (HF), dithiothreitol (DTT), sodium citrate dihydrate, 1-pentanol tetraethyl orthosilicate

(TEOS), N-(3-dimethylaminopropyl)-N'-ethylcarbodiimide hydrochloride (EDC), (3aminopropyl)-triethoxysilane (APTES), and phosphate-buffered saline were purchased from Sigma-Aldrich and used as received. 3-(N-morpholino)propanesulfonic acid (MOPS) was obtained from Acros Organics. Sodium acetate (NaOAc), 2-( $N$-morpholine)ethane-sulfonic acid (MES), and ammonia were purchased from Merck. Pyridine dithioethylamine hydrochloride (PDA-HCl) was obtained from Shanghai Speed Chemical Co. Ltd., China. Alexa Fluor 488 goat anti-mouse IgG, Alexa Fluor® 633 hydrazide (AF633) reactive dyes, Dulbecco's modified Eagle's medium (DMEM), GlutaMax, heat-inactivated fetal bovine serum (HI-FBS), Dulbecco's Phosphate-Buffered Saline (DPBS), $\mathrm{CO}_{2}$-independent medium, CellLight Early EndosomesGFP, CellLight Lysosomes-RFP and CellLight Tubulin-GFP, and Hoechst 33342 were purchased from Life Technologies. Mouse anti- $\alpha$-tubulin monoclonal antibody (clone B-5-1-2) was purchased from Sigma-Aldrich. Mouse anti-human LAMP1 monoclonal antibody (clone H4A3) was purchased from BD Pharmingen. Ultrapure water with resistance greater than $18 \mathrm{M} \Omega$ cm was obtained from an inline Millipore RiOs/Origin system (Millipore Corporation, USA).

Preparation of $\mathrm{PMA}_{S H}$ Particles: $\mathrm{PMA}_{\mathrm{SH}}$ with $20 \%$ thiol-modification and $\mathrm{PMA}_{\mathrm{SH}}$ particles were prepared using our previously reported protocols. ${ }^{20}$ Briefly, approximately $3 \mathrm{mg}$ of APTES-modified MS particles were dispersed in $5 \mathrm{mg} \mathrm{mL}^{-1}$ of $\mathrm{PMA}_{\mathrm{SH}}$ solution at $\mathrm{pH} 4.5$ (600 $\mu \mathrm{L}$ of $\mathrm{NaOAc}$ buffer, $50 \mathrm{mM}$ ) under constant shaking overnight. Subsequently, the particles were isolated by centrifugation and washed twice with $\mathrm{NaOAc}$ buffer. The pellet was dispersed in 50 
$\mu \mathrm{L}$ of NaOAc buffer and exposed to a $10 \mathrm{mM}$ solution of chloramine $\mathrm{T}$ in NaOAc buffer (pH 6 , $50 \mathrm{mM}$ ) for $2 \mathrm{~min}$. After two washing cycles with PBS buffer, the MS templates were dissolved with a $2 \mathrm{M} \mathrm{HF} / 8 \mathrm{M} \mathrm{NH}_{4} \mathrm{~F}$ solution ( $\left.\mathrm{pH} \sim 5\right)$. Caution! HF is highly toxic. Extreme care should be taken when handling HF solution and only small quantities should be prepared. The resultant $\mathrm{PMA}_{\mathrm{SH}}$ particles were washed three times with Milli-Q water and labeled with AF633 via EDCmediated amide bond formation between the carboxyl groups of PMA and hydrazide groups of AF633 in DPBS buffer. The fluorescently labeled PMA $\mathrm{SH}_{\mathrm{SH}}$ particles were counted using a CyFlow Space (Partec GmbH) flow cytometer with $488 \mathrm{~nm}$ and $633 \mathrm{~nm}$ lasers, as reported previously. ${ }^{33}$ The flow cytometer counts the particle number based on the particle fluorescence and scattering signals in the known volume.

Cell Culture: HeLa cells were maintained in DMEM media with the addition of $1 \%(\mathrm{v} / \mathrm{v})$ GlutaMax and $10 \%(\mathrm{v} / \mathrm{v}) \mathrm{HI}-\mathrm{FBS}$ at $37{ }^{\circ} \mathrm{C}$ in a $5 \% \mathrm{CO}_{2}$ humidified atmosphere and subcultured prior to confluence using trypsin.

Cellular Association Analysis: HeLa cells were plated at a density of $7.5 \times 10^{4}$ cells per well into 24-well plates and allowed to adhere overnight. Cells were then incubated with AF633labeled $\mathrm{PMA}_{\mathrm{SH}}$ particles at a capsule-to-cell ratio of 100:1 for different time intervals in a total volume of $1 \mathrm{~mL}$ complete growth DMEM media $\left(37^{\circ} \mathrm{C}, 5 \% \mathrm{CO}_{2}\right)$. After treatment, the cells were washed with DPBS three times and harvested by trypsinization and centrifugation at $400 \mathrm{~g}$ for $5 \mathrm{~min}$. The cell pellet was resuspended in DPBS and analyzed by flow cytometry. Flow cytometry analysis was performed using a CyFlow Space (Partec GmbH) flow cytometer using lasers with excitation wavelengths of $488 \mathrm{~nm}$ and $633 \mathrm{~nm}$. In each measurement at least 10000 cells were analyzed. 
Internalization Analysis by Imaging Flow Cytometry: Cells treated with particles were prepared as described above. Briefly, $9 \times 10^{5}$ cells were seeded into T25 flasks and treated with AF633-labeled PMA HCs at a capsule-to-cell ratio of 100:1 for $24 \mathrm{~h}$ in complete growth DMEM media. After the treatment, the cells were washed with DPBS three times. Cells were further labeled with Vybrant CFDA SE Cell Tracer $(0.5 \mu \mathrm{M})$ according to the manufacturer's protocol. Cells were subsequently trypsinized and collected by centrifugation at $400 \mathrm{~g}$ for $5 \mathrm{~min}$. Cold DPBS was used to resuspend cells and keep on ice until analysis using imaging flow cytometry. Images of 5000 cells and the capsule fluorescence intensities were acquired. The internalization analysis was performed using the built-in internalization feature of IDEAS software on single focused cells associated with capsules.

Intracellular Fate of $P M A_{S H}$ Particles by Deconvolution Microscopy: HeLa cells were plated at $3 \times 10^{4}$ cells per well into 8 -well Lab-Tek I chambered coverglass slides (Thermo Fisher Scientific, Rochester) and allowed to adhere overnight. The cells were then incubated with AF633-labeled PMA $\mathrm{PH}_{\mathrm{SH}}$ particles at a capsule-to cell ratio of 100:1 for $24 \mathrm{~h}$ in complete growth DMEM media $\left(37^{\circ} \mathrm{C}, 5 \% \mathrm{CO}_{2}\right)$. Following this, the cells were washed with DPBS three times and fixed with $4 \%$ paraformaldehyde for $30 \mathrm{~min}$ at room temperature (RT) of $22{ }^{\circ} \mathrm{C}$ and permeabilized with $0.1 \%$ Triton $\mathrm{x}-100$ in DPBS for $5 \mathrm{~min}$ at RT. Lysosomes were immunostained with anti-LAMP1 antibody $\left(2.5 \mu \mathrm{g} \mathrm{mL}^{-1}\right)$ and AF488-goat anti-mouse $\mathrm{IgG}(2 \mu \mathrm{g}$ $\left.\mathrm{mL}^{-1}\right)$. Nuclei were counterstained with Hoechst $33342\left(2 \mu \mathrm{g} \mathrm{mL} \mathrm{m}^{-1}\right)$. Fluorescence images and optical sections were collected using a deconvolution microscope (DeltaVision, Applied Precision). Images were processed with Imaris 6.3.1 software (Bitplane).

Live Cell Time Lapse Imaging: HeLa cells were plated at $1.5 \times 10^{4}$ cells per well into 8well Lab-Tek I chambered coverglass slides (Thermo Fisher Scientific, Rochester) and allowed 
to adhere overnight. The cells were then incubated with CellLight Early Endosomes-GFP, CellLight Lysosomes-RFP, or CellLight Tubulin-GFP to label early endosomes, lysosomes or microtubulin, respectively. The cells were transduced at a ratio of cell-to-baculovirus of 1:30 and incubated for $24 \mathrm{~h}$ before imaging. Following the transduction, fresh complete DMEM media containing AF633-labeled PMA SH $_{\text {particles }}\left(1.5 \times 10^{6}\right.$ particles/chamber $)$ were added. After the treatment, fresh $\mathrm{CO}_{2}$-independent media with the addition of $1 \%$ GlutaMax and $10 \%$ HI-FBS were added. Time-lapse fluorescence images and optical sections were collected using deconvolution microscopy for a total of $2 \mathrm{~h}$ with $2.5 \mathrm{~min}$ intervals to image intracellular trafficking, or for a total of $24 \mathrm{~h}$ with $10 \mathrm{~min}$ intervals to image cell division. The acquired movies were processed with Imaris 6.3.1 software (Bitplane).

Imaging of Cytokinesis: HeLa cells were plated at $1.5 \times 10^{4}$ cells per well into 8 -well Lab-Tek I chambered coverglass slides and allowed to adhere overnight. The cells were then incubated with AF633-labeled PMA $\mathrm{PH}_{\mathrm{SH}}$ particles $\left(1.5 \times 10^{6}\right.$ particles/chamber $)$ for $24 \mathrm{~h}$ in complete growth DMEM media. The treatment media was then replaced with fresh complete DMEM media and the cells were cultured for an additional $20 \mathrm{~h}$. The cells were subsequently fixed with $4 \%$ paraformaldehyde and permeabilized with $0.1 \%$ Triton x-100 for 5 min at RT. The cells were then immunostained with anti- $\alpha$-tubulin monoclonal antibody (1:2000 dilution in DPBS containing 1\% BSA) and AF488-goat anti-mouse $\operatorname{IgG}\left(2 \mu \mathrm{g} \mathrm{mL} \mathrm{m}^{-1}\right)$. Nuclei were counterstained with Hoechst $33342\left(2 \mu \mathrm{g} \mathrm{mL}^{-1}\right)$. Fluorescence images and optical sections were collected using a deconvolution microscope (DeltaVision, Applied Precision). 152 cells undergoing cytokinesis were identified based on the characteristic structure of microtubules. The particles distributed between two daughters were counted using the particle counting function of the Imaris 6.3.1 software (Bitplane). The segregation deviation (\%) was calculated as follows: 
$(\mathrm{B}-\mathrm{A}) /(\mathrm{B}+\mathrm{A}) \times 100$, where $\mathrm{B}$ and $\mathrm{A}$ represent the number of particles for two daughter cells $(\mathrm{B} \geq$ A). The frequency of segregation deviation was plotted using software Prism 5 (GraphPad).

Proteomic Analysis Using 2D-DIGE: Harvested cells from six biological replicates of untreated and particles treated with HeLa cells were lysed in RIPA buffer containing the proteolytic inhibitors Aprotinin $\left(100 \mu \mathrm{g} \mathrm{mL}^{-1}\right)$, Leupeptin $\left(500 \mu \mathrm{g} \mathrm{mL} \mathrm{m}^{-1}\right)$, and Pepstatin A $(70 \mu \mathrm{g}$ $\mathrm{mL}^{-1}$ ) (American Bioanalytical) for $4 \mathrm{~h}$ at $4{ }^{\circ} \mathrm{C}$. Protein concentrations of cell lysates were determined using a 2-D Quant Kit (GE Healthcare) according to the manufacturer's instructions. Subsequently, protein $(100 \mu \mathrm{g})$ was precipitated using a 2-D Clean-Up Kit (GE Healthcare) according to the manufacturer's instructions. Proteins were then dissolved in $7 \mathrm{M}$ urea, $2 \mathrm{M}$ thiourea, 4\% (w/v) CHAPS, and $30 \mathrm{mM}$ Tris- $\mathrm{HCl} \mathrm{pH}$ 8.5. Labeling reactions were performed in a $45 \mu \mathrm{L}$ volume with $30 \mu \mathrm{g}$ of the protein lysates, in the presence of 400 pmol of Cy2-, Cy3- or Cy5-dyes (minimal labeling dyes, GE Healthcare), by implementation of a dye-swapping strategy. ${ }^{34}$ Three extracts from untreated HeLa cells were labeled with Cy3, while three extracts from cells that had been treated with particles were labeled with Cy5. In a complementary manner, three extracts of untreated cells were labeled with Cy5, and three extracts of cells treated with particles labeled with Cy3. Six mixtures of the paired samples (30 $\mu \mathrm{g}$ each) were also labeled with Cy2 dye, the internal standard used for the 2D-DIGE procedure. The labeling was performed for $30 \mathrm{~min}$ on ice, in the dark, and chased with $1 \mathrm{mM}$ lysine. Six sample mixtures, made of appropriate Cy3- and Cy5-labeled pairs and a Cy2-labeled control, were supplemented with $1 \%$ v/v IPG buffer, pH 3-10 NL (GE Healthcare), 1.4\% v/v DeStreak reagent (GE Healthcare), and $0.2 \%$ w/v DTT to a final volume of $300 \mu \mathrm{L}$ in $7 \mathrm{M}$ urea, $2 \mathrm{M}$ thiourea, and $4 \%$ CHAPS. The mixtures (90 $\mu \mathrm{g}$ of total protein content) were used for passive hydration of immobilized $\mathrm{pH}$ gradient IPG gel strips (24 cm, pH 3-10 NL) for $16 \mathrm{~h}$ at $20{ }^{\circ} \mathrm{C}$. Isoelectric 
focusing (IEF) was performed on an IPGphor II apparatus (GE Healthcare) up to $8000 \mathrm{~V} \mathrm{~h}^{-1}$ at $20{ }^{\circ} \mathrm{C}$ (current limit, $50 \mathrm{uA}$ /strip). The strips were equilibrated in $6 \mathrm{M}$ urea, $2 \%$ SDS, $20 \%$ glycerol, and $0.375 \mathrm{M}$ Tris- $\mathrm{HCl}(\mathrm{pH} 8.8$ ) for $15 \mathrm{~min}$, in the presence of $0.5 \% \mathrm{w} / \mathrm{v} \mathrm{DTT}$, and then in the presence of $4.5 \% \mathrm{w} / \mathrm{v}$ iodoacetamide in the same buffer for an additional $15 \mathrm{~min}$ in the dark. The equilibrated IPG strips were finally transferred onto 4-20\% polyacrylamide gels, within low-fluorescence glass plates (ETTAN-DALT 6 system, GE Healthcare). The seconddimension SDS-PAGE was performed on a DALT II electrophoresis unit (GE Healthcare) at 1 W/gel for $16 \mathrm{~h}$. Gels were scanned on a Typhoon 9400 variable mode imager (GE Healthcare), with the indicated excitation/emission wavelengths for Cy2 (488/520 nm), Cy3 (532/580 nm), and Cy5 $(633 / 670 \mathrm{~nm})$ with a pixel size of 100 micrometers. Images were acquired with the ImageQuant software (GE Healthcare) and analyzed using the DeCyder 6.0 software (GE Healthcare). A DeCyder differential in-gel-analysis (DIA) module was used for spot detection and pair-wise comparison of each sample ( $\mathrm{Cy} 3$ and $\mathrm{Cy} 5)$ to the $\mathrm{Cy} 2$ mixed standard present in each gel. The DeCyder biological variation analysis (BVA) module was then used to simultaneously match all of the protein-spot maps from the gels, and to calculate average abundance ratios and $\mathrm{P}$ values across the six replicate sets of samples (Student's T-test). After spot matching with the master gel from the analytical step in the BVA module of DeCyder software, 2D gels were silver stained and spots picked for in gel tryptic digest and MS analysis. Excised gel spots were digested as previously described ${ }^{35}$ using iodoacetamide for cysteine alkylation. Digested protein spot extracts were loaded onto an Ultimate 3000 UPLC (Dionex, Thermo Scientific) fitted with a nano trap column (Acclaim PepMap100 C18, $100 \mu$ m i.d. $\times 2$ $\mathrm{cm}, 5 \mu \mathrm{m}, 100 \AA$ ) at $10 \mu \mathrm{L} \min ^{-1}$ in $5 \%$ buffer B. Peptides were then resolved on an Acclaim PepMap RSLC C18 column (75 $\mu$ m i.d. x $15 \mathrm{~cm}, 2 \mu \mathrm{m}, 100 \AA)$ at $300 \mathrm{~nL} \mathrm{~min}^{-1}$ using a $30 \mathrm{~min}$ 
gradient from 5-55\% buffer B (buffer A: 0.1\% formic acid, buffer B: $95 \%$ acetonitrile / $0.1 \%$ formic acid). The column was maintained at $40{ }^{\circ} \mathrm{C}$. The column eluate was connected online to a QExactive mass spectrometer (Thermo) through a nanoelectrospray source. Parent ion scans (350-2000 m/z, $70 \mathrm{k}$ resolution, AGC target 1e6, $60 \mathrm{~ms}$ max ion time) were used to select up to 10 multiply charged ions to subject to MSMS (17.5 k resolution, AGC target 5e5, $120 \mathrm{~ms}$ maximum ion time, isolation width $2.5 \mathrm{~m} / \mathrm{z}$, NCE 28.0) using an intensity threshold of $1.3 \mathrm{e} 5$ (underfill ratio of 3\%). Dynamic exclusion was employed for $15 \mathrm{sec}$. Spectra were converted to mzXML format using MSConvert (ProteoWizard version 3.0.3631). Spectra were searched using $\mathrm{X}$ !Tandem through gpm-xe manager (version 2.2.1) against human proteins from Ensembl (build GRCh37.64, with reversed sequences). Search parameters are included trypsin cleavage specificity, fixed cysteine carbamidomethylation, variable methionine oxidation, parent mass accuracy 20 ppm, fragment mass accuracy 50 ppm, and one missed cleavage.

Pathway Analysis: The list of regulated proteins identified by 2D-DIGE/MS was analyzed by pathway analysis using the network-building tool Ingenuity Pathway Analysis (IPA) (Ingenuity Systems, www.ingenuity.com). IPA combines the currently available data for gene, protein, chemical, normal cellular and disease processes, signaling and metabolic pathways to generate interaction networks. Significance was measured using Fisher's $t$-test, which relies on $p$ values to determine whether the null hypothesis should be accepted or rejected. Molecular functions with a $p$-value $<0.01$ were considered significant.

\section{ACKNOWLEDGMENT}

This work was supported by the Australian Research Council under the Australian Laureate Fellowship (F.C., FL120100030) and Discovery Early Career Researcher Award (Y.Y., 
DE130100488), and by the National Health and Medical Research Council (NHMRC) Program Grant 487922 (F.C.).

Supporting Information Available: Cell viability following exposure to PMA $\mathrm{AH}_{\mathrm{SH}}$ particles, 2DDIGE, table of differentially expressed proteins identified and alignments of protein sequences from spots 18 and 19. This material is available free of charge via the Internet at http://pubs.acs.org.

\section{AUTHOR INFORMATION}

Corresponding Authors

*Address correspondence to fcaruso@unimelb.edu.au, ed.nice@monash.edu

\section{Author Contributions}

\$These authors contributed equally. 
a)
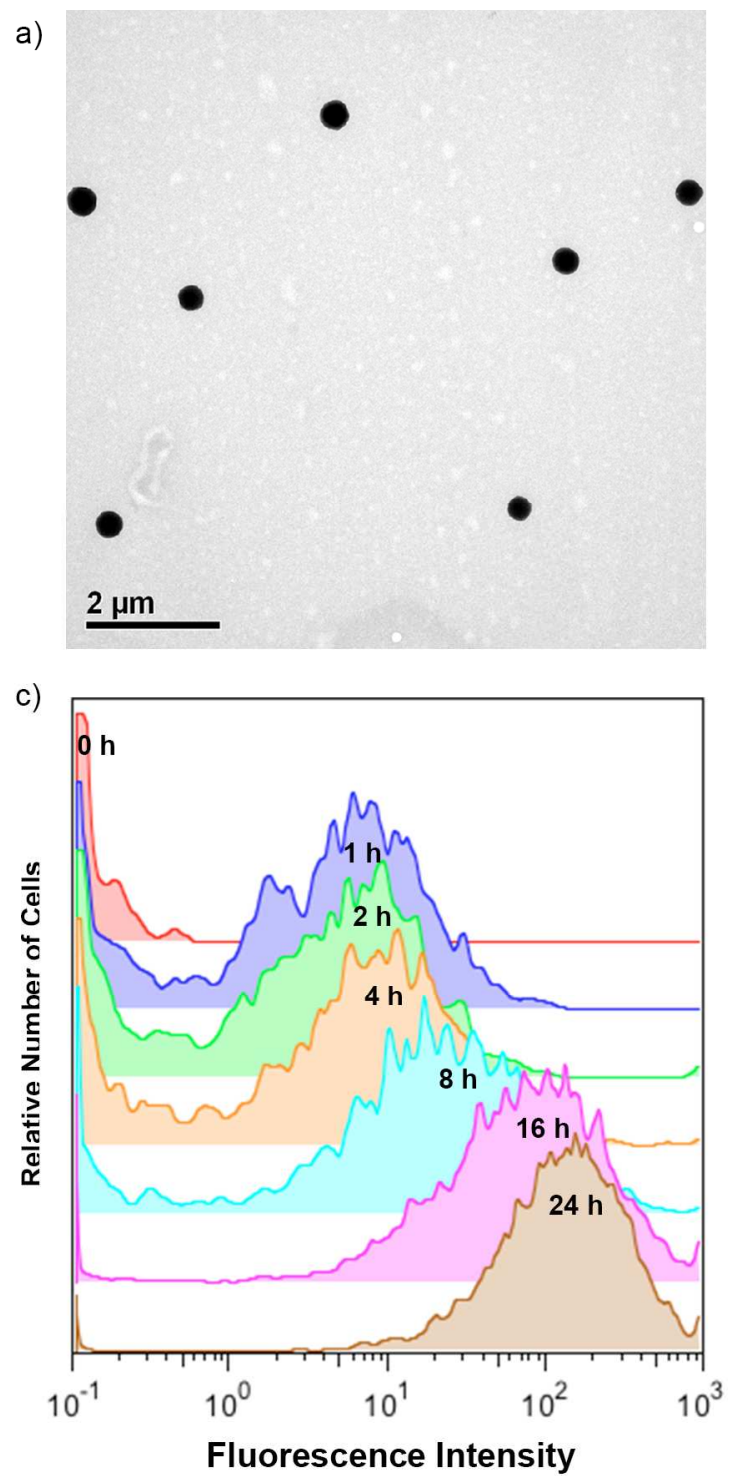

b)

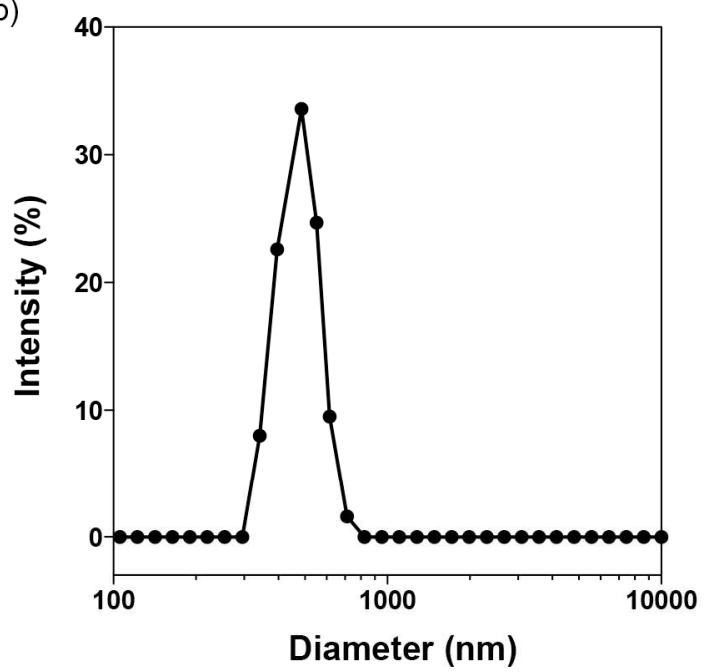

d)

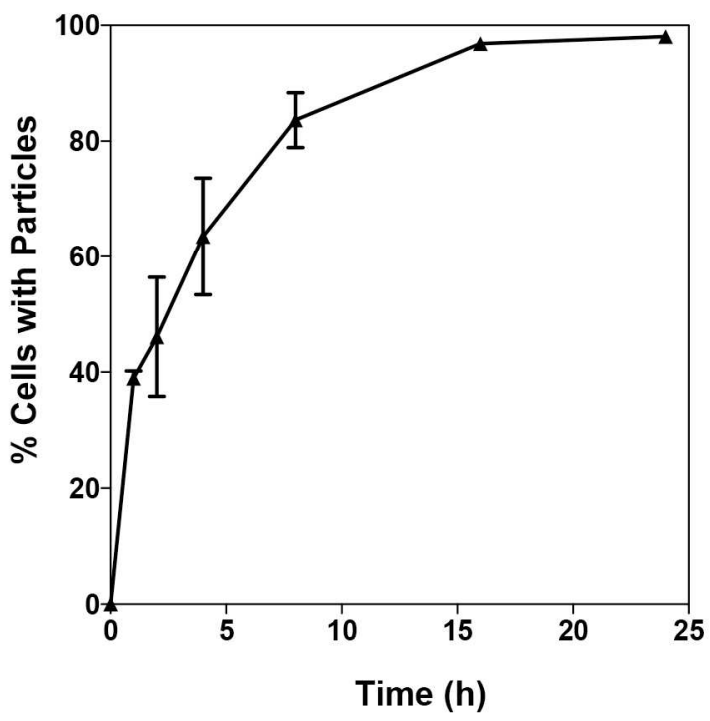

Figure 1. a) TEM image of $\mathrm{PMA}_{\mathrm{SH}}$ particles. b) Size distribution of $\mathrm{PMA}_{\mathrm{SH}}$ particles measured by DLS in $10 \mathrm{mM}$ phosphate buffer, pH7.4. Time-dependent cellular association of AF633labeled PMA $A_{S H}$ NPPs with HeLa cells: c) Representative flow cytometry histograms showing the number of cells associated with particles; and d) Percentage of cells with particles. Data are the mean \pm standard error of two independent experiments, and at least 10000 cells were analyzed in each experiment. Flow cytometry analysis was performed after the cells were incubated with 
particles at a 100:1 particle-to-cell ratio over a $24 \mathrm{~h}$ incubation period at $37{ }^{\circ} \mathrm{C}$ and $5 \% \mathrm{CO}_{2}$.
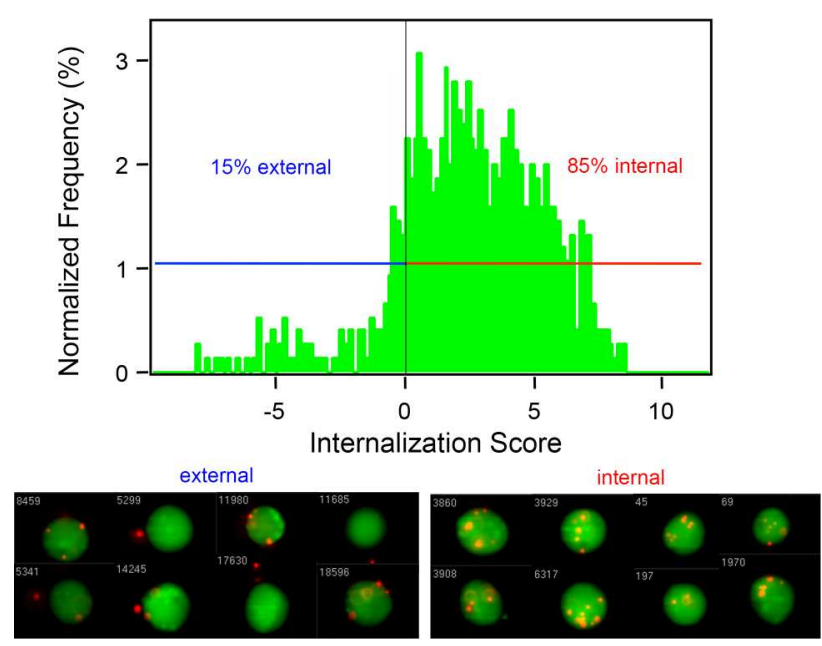

Figure 2. Quantification of the internalization of AF633-labeled PMA $\mathrm{ASH}_{\mathrm{SH}}$ particles in HeLa cells by imaging flow cytometry. Cells were incubated with particles at a particle-to-cell ratio of 100:1 for $24 \mathrm{~h}$. Cells with internalized particles were selected by choosing the cell population with a positive internalization score. Representative images of cells with internalized particles (right panel) and cells with external surface bound particles (left panel). 


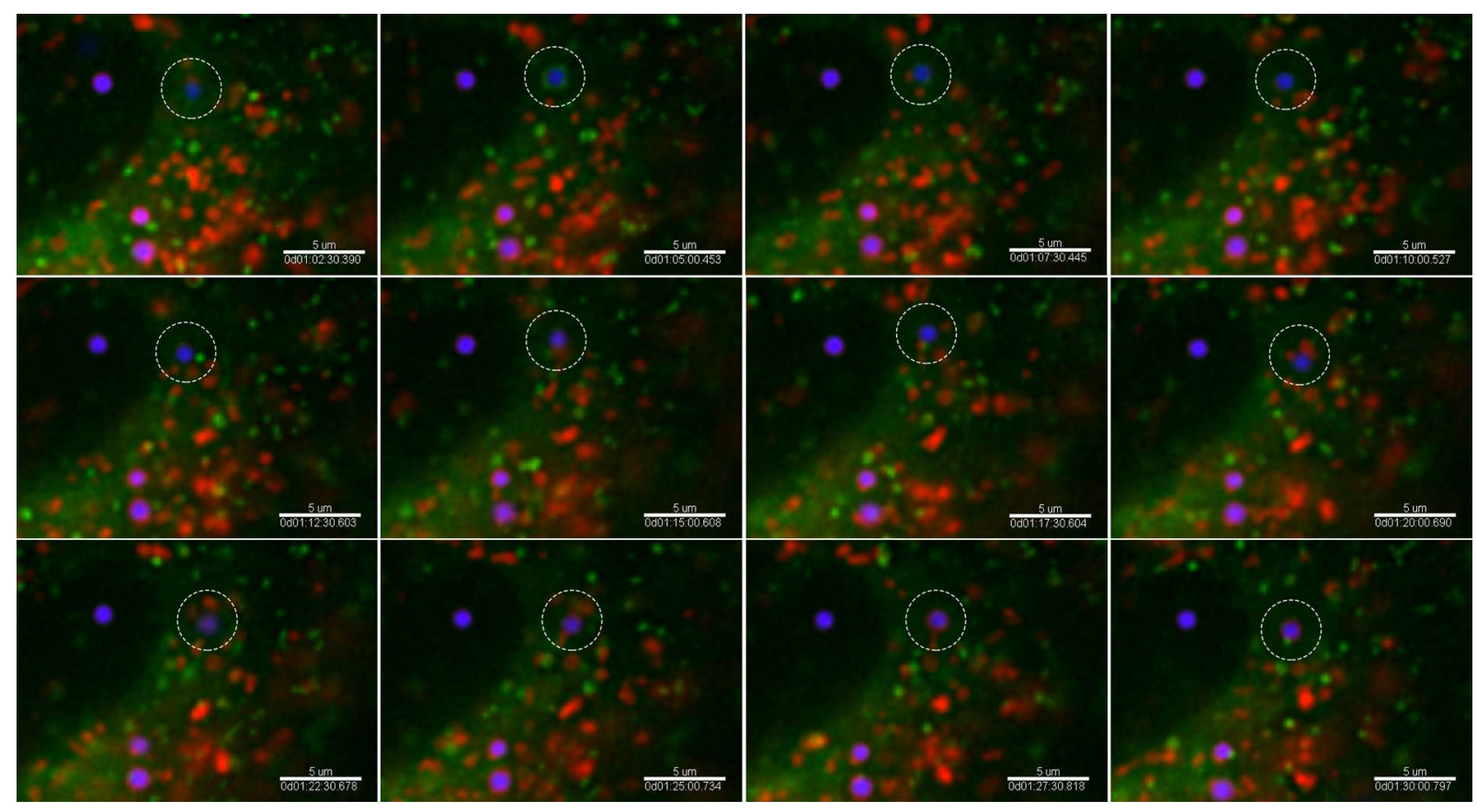

Figure 3. Intracellular trafficking of AF633-labeled PMA transiently transduced with GFP-early endosomes (green) and RFP-lysosomes (red), subsequently incubated with the $\mathrm{PMA}_{\mathrm{SH}}$ particles (blue). Time-lapse deconvolution microscopy images were taken for $4 \mathrm{~h}$ following incubation with an interval of $2.5 \mathrm{~min}$ between sequential images. Scale bars $=5 \mu \mathrm{m}$. 


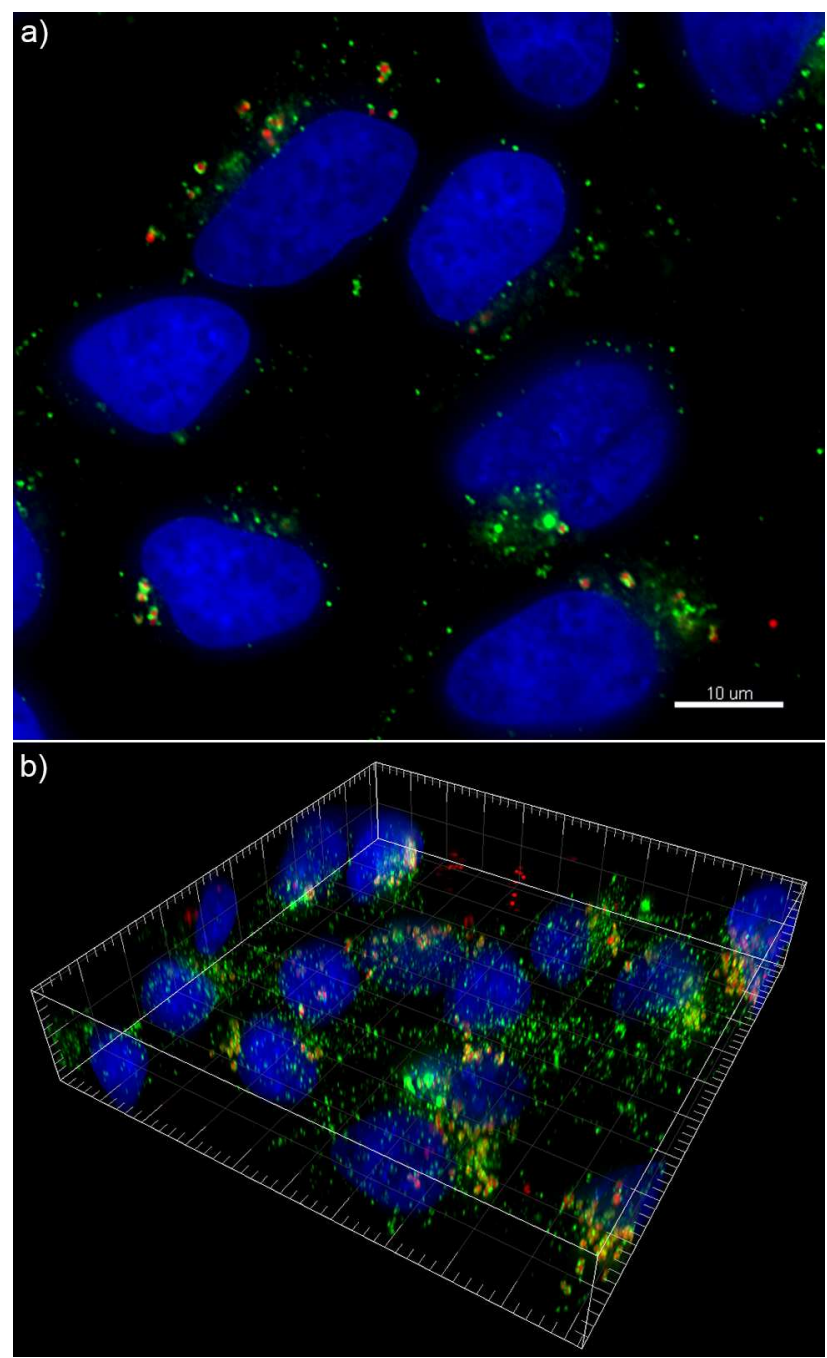

Figure 4. Intracellular distribution of AF633-labeled PMA ${ }_{S H}$ particles in HeLa cells. Cells were incubated with $\mathrm{PMA}_{\mathrm{SH}}$ particles (red) for $24 \mathrm{~h}$. Lysosomes were immunostained with antiLAMP1 antibody (green) and nuclei were counterstained with Hoechst 33342 (blue). a) Focal plane deconvolution microscopy image. Scale bar $=10 \mu \mathrm{m}$. b) 3D deconvolution microscopy image. Axis tick $=1 \mu \mathrm{m}$. 


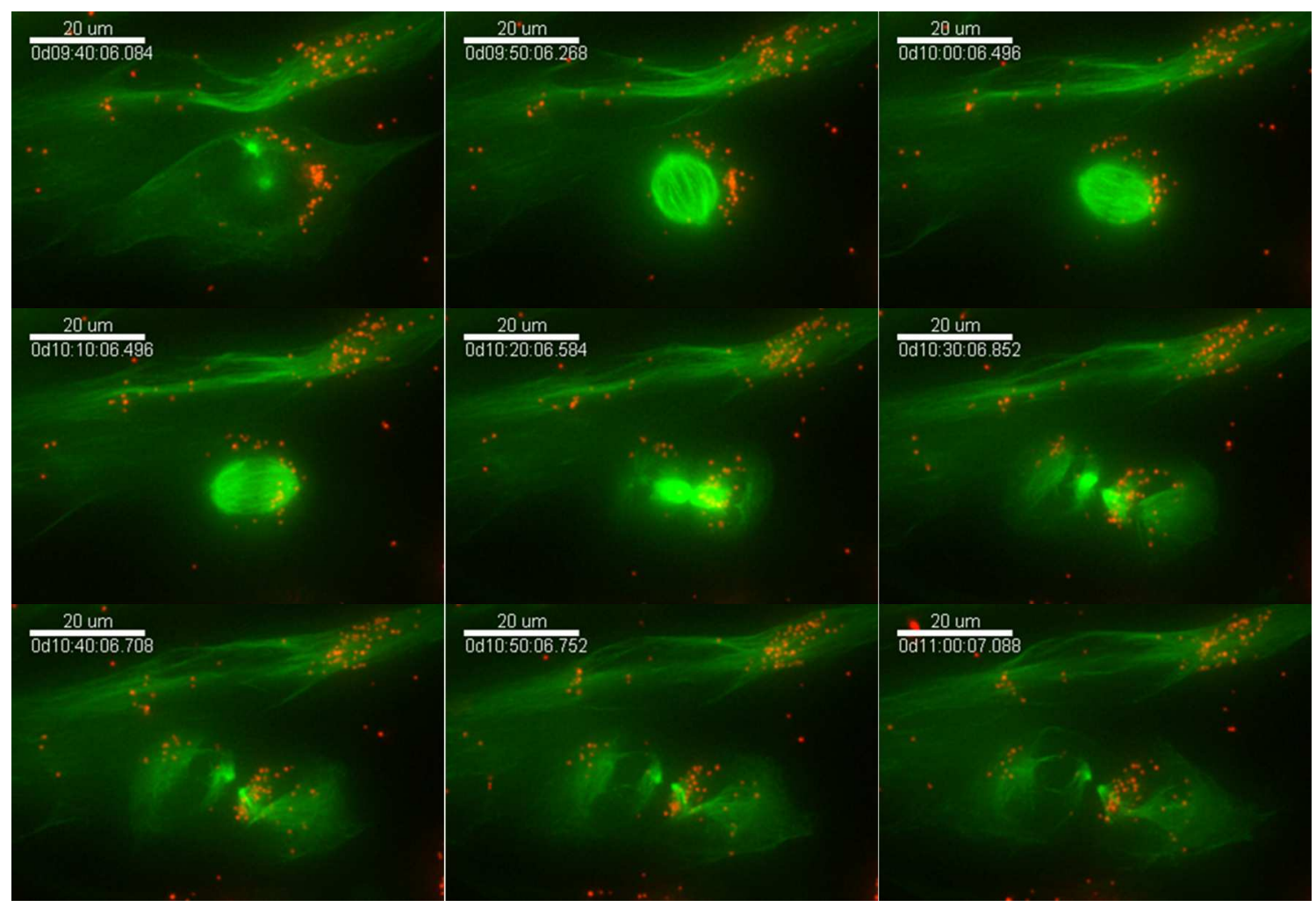

Figure 5. Distribution of AF633-labeled $\mathrm{PMA}_{\mathrm{SH}}$ particles during mitosis. Cells were transiently transduced with GFE-tubulin (green) and incubated with the particles for $24 \mathrm{~h}$. The following cell cycle was monitored by time-lapse deconvolution microscopy. Images were taken with an interval of $10 \mathrm{~min}$ for $24 \mathrm{~h}$. Scale bars $=20 \mu \mathrm{m}$. 
a)

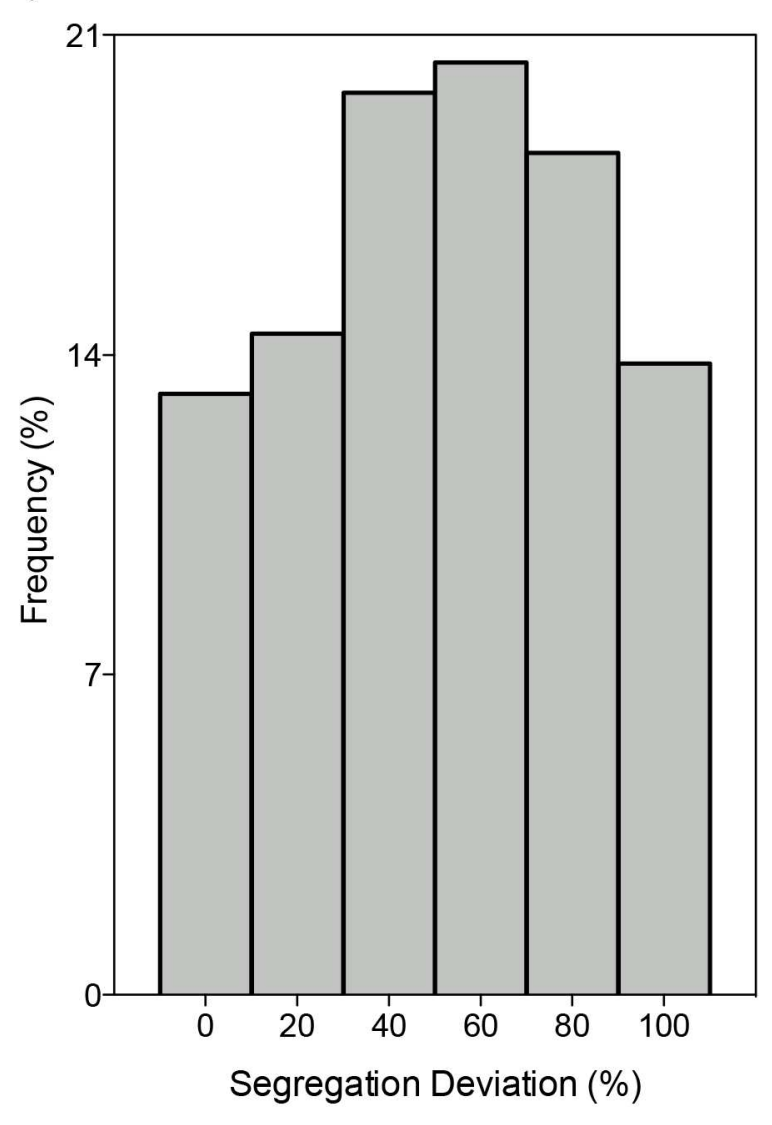

b)

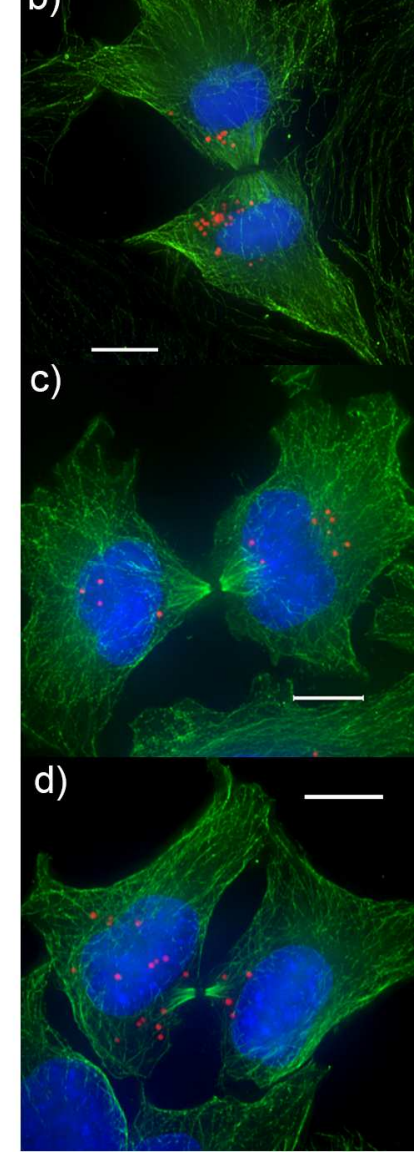

Figure 6. Quantitative analysis of mitotic partitioning of AF633-labeled PMA $\mathrm{SH}_{\mathrm{SH}}$ particles in HeLa cells. Cells were incubated with the particles and immunostained with anti- $\alpha$-tubulin monoclonal antibody. 152 cells in cytokinesis were identified, and the number of particles in daughter cells was determined. a) Distribution of segregation deviation for 152 cells. Segregation deviation was calculated as the percentage of the difference to the sum of particles in both daughter cells. b) Representative deconvolution microscopy images of cells undergoing cytokinesis. Microtubules are stained green, nuclei are labeled blue, and particles are shown in red. Scale bars $=10 \mu \mathrm{m}$. 
a)

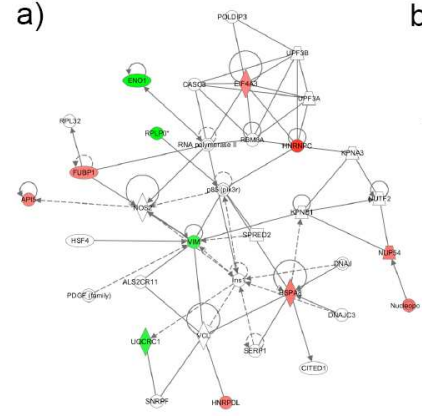

b)
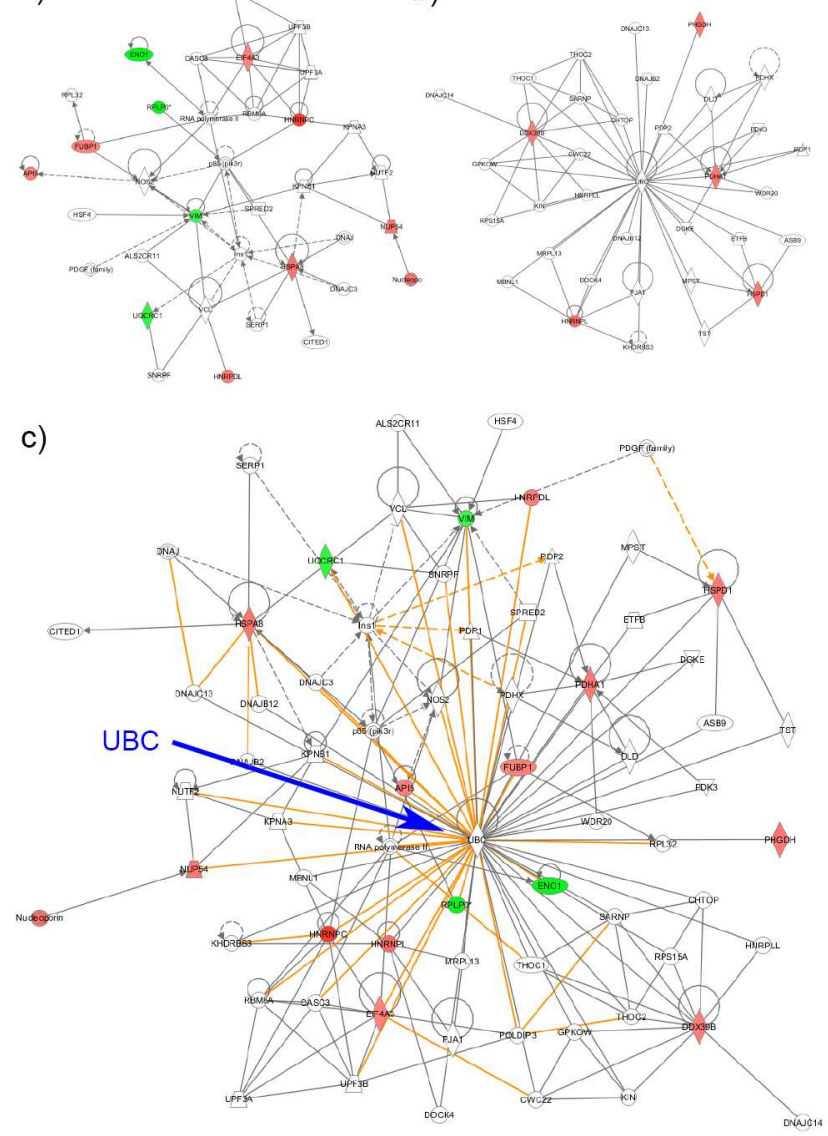

Figure 7. Protein network analysis of dysregulated proteins identified from 2D-DIGE MS/MS. Two standard networks were identified by IPA involved in functions of molecular transport (a and b), protein trafficking (a) and RNA trafficking (b). The merged network (c) highlights the central role of ubiquitin. Identified proteins are shown in red (up-regulated) and green (downregulated) in response to particle treatment. Solid lines represent direct relationships. Dotted lines represent indirect relationships. Lines connecting the proteins indicate known interrelationships from the IPA database. 


\section{REFERENCES}

1. Yan, Y.; Such, G. K.; Johnston, A. P. R.; Best, J. P.; Caruso, F. Engineering Particles for Therapeutic Delivery: Prospects and Challenges. ACS Nano 2012, 6, 3663-3669.

2. Canton, I.; Battaglia, G. Endocytosis at the Nanoscale. Chem. Soc. Rev. 2012, 41, 27182739.

3. Duncan, R.; Richardson, S. C. W. Endocytosis and Intracellular Trafficking as Gateways for Nanomedicine Delivery: Opportunities and Challenges. Mol. Pharm. 2012, 9, 2380-2402.

4. Marsh, M.; McMahon, H. T. The Structural Era of Endocytosis. Science 1999, 285, 215-220.

5. Scita, G.; Di Fiore, P. P. The Endocytic Matrix. Nature 2010, 463, 464-473.

6. Doherty, G. J.; McMahon, H. T. Mechanisms of Endocytosis. Annu. Rev. Biochem. 2009, $78,857-902$.

7. Andrews, R.; Ahringer, J. Asymmetry of Early Endosome Distribution in C. elegans Embryos. PLoS One 2007, 2, e493.

8. Beckmann, J.; Scheitza, S.; Wernet, P.; Fischer, J. C.; Giebel, B. Asymmetric Cell Division within The Human Hematopoietic Stem and Progenitor Cell Compartment: Identification of Asymmetrically Segregating Proteins. Blood 2007, 109, 5494-5501.

9. Liu, K-K.; Wang, C-C.; Cheng, C-L.; Chao, J-I. Endocytic Carboxylated Nanodiamond for The Labeling and Tracking of Cell Division and Differentiation in Cancer and Stem Cells. Biomaterials 2009, 30, 4249-4259.

10. Serda, R. E.; Ferrati, S.; Godin, B.; Tasciotti, E.; Liu, X.; Ferrari, M. Mitotic Trafficking of Silicon Microparticles. Nanoscale 2009, 1, 250-259. 
11. Errington, R. J.; Brown, M. R.; Silvestre, O. F.; Njoh, K. L.; Chappell, S. C.; Khan, I. A.; Rees, P.; Wilks, S. P.; Smith, P. J.; Summers, H. D. Single Cell Nanoparticle Tracking to Model Cell Cycle Dynamics and Compartmental Inheritance. Cell Cycle 2010, 9, 121-130.

12. Summers, H. D.; Rees, P.; Holton, M. D.; Brown, M. R.; Chappell, S. C.; Smith, P. J.; Errington, R. J. Statistical Analysis of Nanoparticle Dosing in A Dynamic Cellular System. Nat. Nanotechnol. 2010, 6, 170-174.

13. Mai, Y.; Eisenberg, A. Self-Assembly of Block Copolymers. Chem. Soc. Rev. 2012, 41, $5969-5985$.

14. Yan, Y.; Such, G. K.; Johnston, A. P. R.; Lomas, H.; Caruso, F. Toward Therapeutic Delivery with Layer-by-Layer Engineered Particles. ACS Nano 2011, 5, 4252-4257.

15. De Koker, S.; Hoogenboom, R.; De Geest, B. G. Polymeric Multilayer Capsules for Drug Delivery. Chem. Soc. Rev. 2012, 41, 2867-2884.

16. Wang, Y.; Angelatos, A. S.; Caruso, F. Template Synthesis of Nanostructured Materials via Layer-by-Layer Assembly. Chem. Mater. 2008, 20, 848-858.

17. Wang, Y.; Price, A. D.; Caruso, F. Nanoporous Colloids: Building Blocks for A New Generation of Structured Materials. J. Mater. Chem. 2009, 19, 6451-6464.

18. Tan, J.; Wang, Y.; Yip, X.; Glynn, F.; Shepherd, R. K.; Caruso, F. Nanoporous Peptide Particles for Encapsulating and Releasing Neutrophic Factors in an Animal Model of Neutrodegeneration. Adv. Mater. 2012, 24, 3362-3366.

19. Zhang, X.; Oulad-Abdelghani, M.; Zelkin, A. N.; Wang, Y.; Haikel, Y.; Mainard, D.; Voegel, J-C.; Caruso, F.; Benkirane-Jessel, N. Poly(L-lysine) Nanostructured Particles for Gene Delivery and Hormone Stimulation. Biomaterials 2010, 31, 1699-1706. 
20. Cui, J.; Yan. Y.; Wang, Y.; Caruso, F. Templated Assembly of pH-Labile Polymer-Drug Particles for Intracellular Drug Delivery. Adv. Funct. Mater. 2012, 22, 4718-4723.

21. Yan, Y.; Johnston, A. P. R.; Dodds, S. J.; Kamphuis, M. M. J.; Ferguson, C.; Parton, R. G.; Nice, E. C.; Heath, J. K.; Caruso, F. Uptake and Intracellular Fate of Disulfide-Bonded Polymer Hydrogel Capsules for Doxorubicin Delivery to Colorectal Cancer Cells. ACS Nano 2010, 4, 2928-2936.

22. De Rose, R; Zelikin, A. N.; Johnston, A. P. R.; Sexton, A.; Chong, S.-F.; Cortez, C.; Mulholland, W.; Caruso, F.; Kent, S. J. Binding, Internalization, and Antigen Presentation of Vaccine-Loaded Nanoengineered Capsules in Blood. Adv. Mater. 2008, 20, 4698-4703.

23. Schweiger, C.; Hartmann, R.; Zhang, F.; Parak, W. J.; Kissel, T. H.; Rivera-Gil, P. Quantification of the Internalization Patterns of Superparamagnetic Iron Oxide Nanoparticles with Opposite Charge. J. Nanobiotechnol. 2012, 10, 28.

24. Bergeland, T.; Widerberg, J.; Bakke, O.; Nordeng, T. W. Mitotic Partitioning of Endosomes and Lysosomes. Curr. Biol. 2001, 11, 644-651.

25. Lai, Z. W.; Yan, Y.; Caruso, F.; Nice, E. C. Emerging Techniques in Proteomics for Probing Nano-Bio Interactions. ACS Nano 2012, 6, 10438-10448.

26. Beckett, P. The Basics of 2D DIGE. Methods Mol. Biol. 2012, 854, 9-19.

27. Hicke, L. Protein Regulation By Monoubiquitin. Nat. Rev. Mol. Cell Biol. 2001, 2, 195201.

28. Clague, M. J.; Liu, H.; Urbé, S. Governance of Endocytic Trafficking and Signaling by Reversible Ubiquitylation. Dev. Cell 2012, 23, 457-467.

29. Marmor, M. D.; Yarden, Y. Role of Protein Ubiquitylation in Regulating Endocytosis of Receptor Tyrosine Kinases. Oncogene 2004, 23, 2057-2070. 
30. Khor, R.; McElroy, L. J.; Whittaker, G. R. The Ubiquitin-Vacuolar Protein Sorting System Is Selectively Required During Entry of Influenza Virus into Host Cells. Traffic 2003, 4, 857868.

31. Delboy, M. G.; Roller, D. G.; Nicola, A. V. Celluar Proteasome Activity Facilitates Herpes Simplex Virus Entry at A Postpenetration Step. J. Virol. 2008, 82, 3381-3390.

32. Albanese, A.; Tang, P. S.; Chan, W. C. The Effect of Nanoparticle Size, Shape, and Surface Chemistry on Biological Systems. Annu. Rev. Biomed. Eng. 2012, 14, 1-16.

33. Shimoni, O.; Yan, Y.; Wang, Y.; Caruso F. Shape-Dependent Cellular Processing of Polyelectrolyte Capsules. ACS Nano 2013, 7, 522-530.

34. Karp, N. A.; Kreil, D. P.; Lilley, K. S. Determining A Significant Change in Protein Expression with DeCyder During A Pair-Wise Comparison Using Two-Dimensional Difference Gel Electrophoresis. Proteomics 2004, 4, 1421-1432.

35. Shevchenko, A.; Tomas, H.; Havlis, J.; Olsen, J. V.; Mann, M. In-Gel Digestion for Mass Spectrometric Characterization of Proteins and Proteomes. Nat. Protoc. 2007, 1, 2856-2860. 
ToC graphic

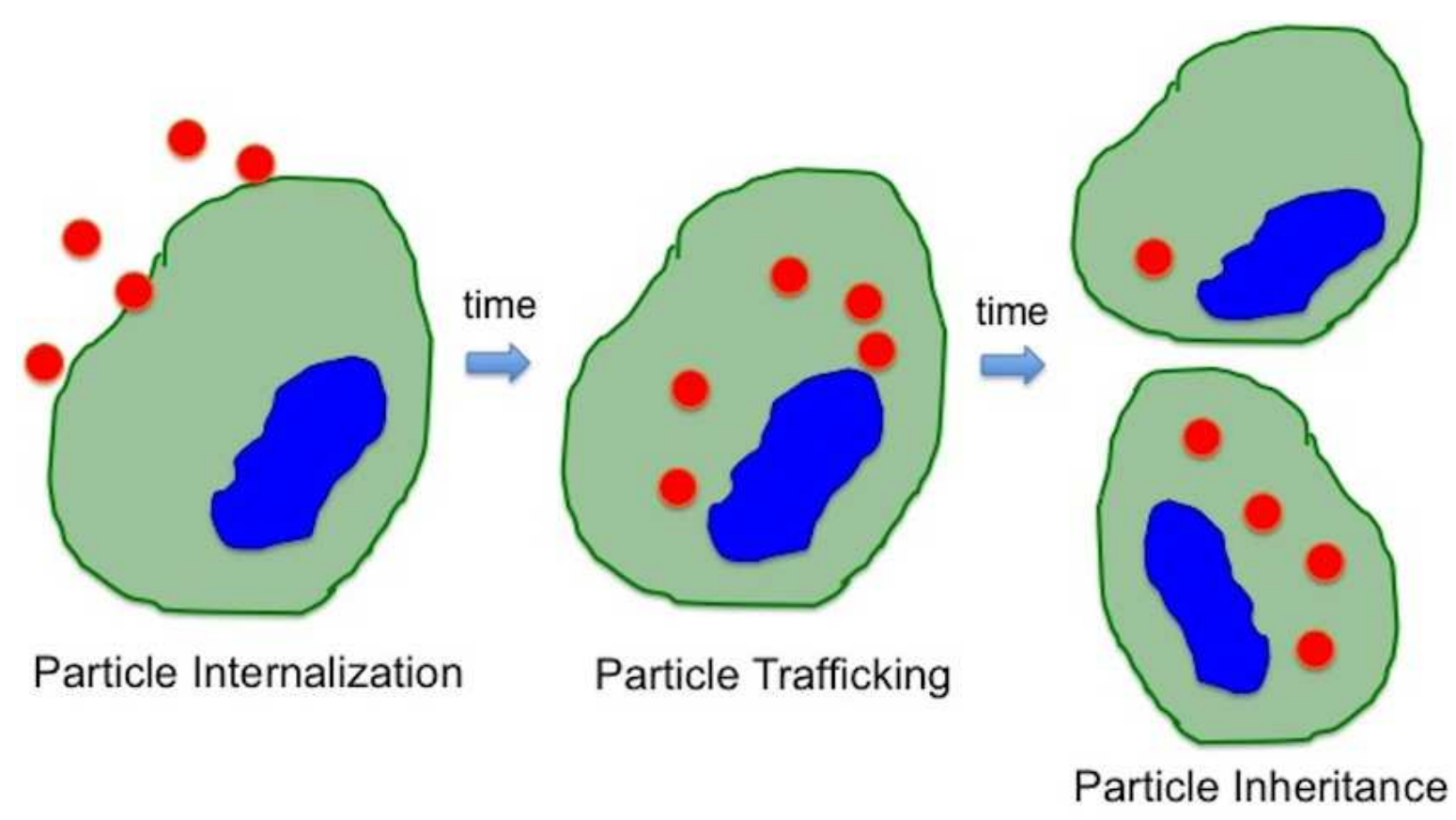

29

30

31

32

33

34

35

36

37

38

39

40

41

42

43

44

45

46

47

48

49

50

51

52

53

54

55

56

57

58

59

60 